\title{
Sulfur-containing amino acids in aged garlic extract inhibit inflammation in human gingival epithelial cells by suppressing intercellular adhesion molecule-1 expression and IL-6 secretion
}

\author{
MASAHIRO OHTANI and TSUBASA NISHIMURA \\ Central Research Institute, Wakunaga Pharmaceutical Co., Ltd., Akitakata, Hiroshima 739-1195, Japan
}

Received September 13, 2019; Accepted December 6, 2019

DOI: $10.3892 /$ br.2019.1269

\begin{abstract}
Aged garlic extract (AGE) contains various biologically active sulfur-containing amino acids, such as $S$-allylcysteine (SAC), $S$-1-propenylcysteine (S1PC) and $S$-allylmercaptocysteine (SAMC). These amino acids have been demonstrated to lower hypertension, improve atherosclerosis and enhance immunity through their anti-inflammatory and antioxidant activities. It was recently reported that the administration of AGE alleviated gingivitis in a clinical trial. In this study, to gain insight into this effect of AGE, the authors examined whether AGE and the three above-mentioned sulfur compounds influence the effects of tumor necrosis factor- $\alpha$ (TNF- $\alpha$ ) in inducing intercellular adhesion molecule-1 (ICAM-1) expression and interleukin-6 (IL-6) secretion in Ca9-22 human gingival epithelial cells. It
\end{abstract}

Correspondence to: Dr Masahiro Ohtani, Central Research Institute, Wakunaga Pharmaceutical Co., Ltd., 1624 Shimokotachi, Koda-cho, Akitakata, Hiroshima 739-1195, Japan

E-mail: ootani_m@wakunaga.co.jp

Abbreviations: AGE, aged garlic extract; ANOVA, analysis of variance; BSA, bovine serum albumin; cDNA, complementary DNA; DAS, diallylsulfide; DMEM, dulbecco's modified eagle's medium; EDTA, ethylenediaminetetraacetic acid; ELISA, enzyme-linked immunosorbent assay; ERK, extracellular signal-regulated kinase; FBS, Fetal bovine serum; h $\beta D 3$, human $\beta$-defensin-3; $\mathrm{HCl}$, hydrochloric acid; HPLC, high performance liquid chromatography; HRP, horseradish peroxidase; HUVECs, human vein endothelial cells; ICAM-1, intercellular adhesion molecule-1; IgG, immunoglobulin G; IL-6, interleukin-6; LC-MS, liquid chromatography-mass spectrometry; LPS, lipopolysaccharide; MMP, matrix metalloproteiase; NF- $\kappa \mathrm{B}$, nuclear factor $\kappa$-light-chain-enhancer of activated B cells; NOD, nucleotide binding oligomerization domain-containing protein; PBS, phosphate-buffered saline; PCR, polymerase chain reaction; P.g., Porphyromonas gingivalis; RANKL, receptor activator of NF- $\kappa \mathrm{B}$ ligand; ROS, reactive oxygen species; S1PC, $S$-1-propenylcysteine; SAC, $S$-allylcysteine; SAMC, $S$-allylmercaptocysteine; SD, standard deviation; TBS, Tris-buffered saline; TNF- $\alpha$, tumor necrosis factor- $\alpha$

Key words: aged garlic extract, gingival epithelial cells, ICAM-1, IL-6, inflammation, sulfur-containing amino acid was found that S1PC reduced the level of ICAM-1 protein induced by TNF- $\alpha$ possibly through post-translational levels without affecting the TNF- $\alpha$-induced mRNA expression. However, SAC and SAMC had no effect. It was also confirmed the inhibitory effect of an antimicrobial peptide [human- $\beta$ defensin-3 (h $\beta \mathrm{D} 3$ )] and found that the inhibitory effects of hbD3 and S1PC were synergistic. On the other hand, the TNF- $\alpha$-induced IL- 6 secretion was attenuated by SAC and SAMC in a dose-dependent manner, whereas S1PC was ineffective. In addition, SAC and SAMC, but not S1PC inhibited the phosphorylation of the transcription factor nuclear factor $\kappa$-light-chain-enhancer of activated $\mathrm{B}$ cells $(\mathrm{NF}-\kappa \mathrm{B})$, which is involved in the expression of inflammatory molecules, suggesting that the anti-inflammatory effects of SAC and SAMC are mediated, at least partly, by NF- $\kappa \mathrm{B}$. On the whole, the findings of this study suggest that the three sulfur amino acids in AGE function synergistically in alleviating inflammation in human gingival epithelial cells.

\section{Introduction}

Gingivitis is a gingival inflammation triggered by periodontal pathogens present in oral biofilms (1). Unless some physical treatments, such as plaque control and scaling are administered, gingivitis becomes more severe and develops into periodontitis with more severe inflammation, leading to the destruction of connective tissues, the absorption of alveolar bones and tooth loss $(1,2)$. It has been demonstrated that excessive inflammation in the gingival tissue, as well as an immune reaction triggered by the increased number of periodontal pathogens, such as Porphyromonas gingivalis (P.g.), plays an important role in the severity and progression of periodontal diseases $(3,4)$. Thus, the control of inflammation may help to delay disease progression or recover severe symptoms in periodontal diseases.

Aged garlic extract(AGE) is prepared by aging garlic(Allium sativum $\mathrm{L}$.) for a period of $>10$ months in aqueous ethanol and contains pharmacologically active sulfur-containing amino acids, such as $S$-allylcysteine (SAC), $S$-1-propenylcysteine (S1PC) and $S$-allylmercaptocysteine (SAMC). In human and animal studies, AGE and these sulfur compounds have been shown to exert beneficial effects, such as the improvement of atherosclerosis $(5,6)$, decrease of high blood pressure $(7,8)$ and the modulation of immunity $(9,10)$. These effects are possibly 
ascribed, at least in part, to the anti-inflammatory $(9,11)$ and/or antioxidant $(12,13)$ activities of sulfur compounds in AGE.

It has been reported that several naturally occurring substances, such as curcumin and theaflavin alleviate the absorption of alveolar bones in animal periodontitis models $(4,14)$. It has also been demonstrated that one of the sulfur-containing compounds present in garlic, diallylsulfide (DAS), reduces inflammatory reactions elicited by P.g.-derived lipopolysaccharide (LPS) in human gingival fibroblast cells (15). Furthermore, DAS and another garlic sulfur compound, alliin, have been shown to inhibit the growth of periodontal microbials (16-18). These findings suggest that sulfur compounds in garlic attenuate moderate or severe inflammation occurring in gingival tissues of gingivitis and periodontitis. Recently, a clinical study demonstrated that the intake of AGE significantly improved gingivitis (1). However, the mechanisms through which AGE attenuates gingivitis remain to be fully elucidated. In this study, the authors examined whether SAC, S1PC and SAMC in AGE exert anti-inflammatory effects against tumor necrosis factor- $\alpha$ (TNF- $\alpha$ )-induced inflammatory reactions in the human gingival epithelial cell line, Ca9-22.

\section{Materials and methods}

Aged garlic extract (AGE) and sulfur compounds. AGE was prepared as previously described (12). Briefly, AGE was manufactured according to the following steps: Originally grown raw garlic (A sativum L.) was cut into slices, immersed in aqueous ethanol, and extracted for $>10$ months at room temperature (12). The sulfur-containing amino acids, S1PC, $\mathrm{SAC}$ and SAMC, are produced during the aging process of raw garlic in $50 \%$ ethanol solution for $>10$ months (19). The purification and structure determination of sulfur compounds in AGE was performed by high performance liquid chromatography (HPLC) and liquid chromatography-mass spectrometry (LC-MS) systems as previously described (9).

Reagents. Dulbecco's modified Eagle's medium (DMEM, D6046) and WST-1 reagent (501594401) were purchased from Sigma-Aldrich. Fetal bovine serum (FBS, 10270), $0.05 \%$ trypsin/EDTA solution (25300-054), Halt protease and phosphatase inhibitor single-use cocktail (1861280) and TRIzol reagent (15596018) were from Thermo Fisher Scientific. Penicillin/streptomycin (164-25251) and recombinant human TNF- $\alpha$ (207-15261) were from Wako Pure Chemical Industries. Human $\beta$-defensin-3 (h $\beta$ D3, 4382-s) was from Peptide Institute Inc. Anti-intercellular adhesion molecule-1 (ICAM-1) (4915S), anti-phosphorylated nuclear factor $\kappa$-light-chain-enhancer of activated B cells $(\mathrm{NF}-\kappa \mathrm{B})$ p65 (3033) antibodies and a horseradish peroxidase (HRP)-conjugated rabbit immunoglobulin G (IgG) (7074S) were from Cell Signaling Technologies. An anti-NF-кB p65 antibody (sc-109X) was from Santa Cruz Biotechnology. RIPA lysis buffer (20-188) was purchased from Merck Millipore. An HRP-conjugated anti- $\beta$-actin antibody (PM053-7) was from MBL Life Science.

Cells and cell culture. The human gingival epithelial cells, Ca9-22 (JCRB0625, Lot. 11182016, Biomedical Innovation, Health and Nutrition Research Institute) were cultured in
DMEM containing 10\% fetal bovine serum, 100,000 units $/ \mathrm{ml}$ penicillin and $100 \mu \mathrm{g} / \mathrm{ml}$ streptomycin in $5 \% \mathrm{CO}_{2}$ at $37^{\circ} \mathrm{C}$. The Ca9-22 cells were subcultured 2 or 3 times per week. For pharmacological experiments, the cells were seeded onto a 6 - or 12 -well plate at the density of 1 to $2 \times 10^{5}$ cells per well and cultured for 36 to $48 \mathrm{~h}$. When they reached full confluency, the cells were treated with TNF- $\alpha(100 \mathrm{ng} / \mathrm{ml})$ in the absence or presence of AGE (0.01-1 mg/ml), S1PC, SAC and SAMC (each at 1 to $100 \mu \mathrm{M}$ ) for the $3,6,12$ or $24 \mathrm{~h}$. In the experiment with cycloheximide (CHX, Fig. 4), the cells were pre-treated with TNF- $\alpha(100 \mathrm{ng} / \mathrm{ml})$ for $12 \mathrm{~h}$, and then treated with S1PC $(10 \mu \mathrm{M})$ in the absence or presence of CHX $(10 \mu \mathrm{M})$ for $6 \mathrm{~h}$.

Interleukin (IL)-6 secretion. Following treatment of the cells with TNF- $\alpha(100 \mathrm{ng} / \mathrm{ml})$ in the absence or presence of AGE (0.01-1 mg/ml), S1PC, SAC or SAMC (each at 1 to $100 \mu \mathrm{M}$ ) for $6 \mathrm{~h}$, an aliquot of culture medium was collected and frozen at $-80^{\circ} \mathrm{C}$ until use. The IL- 6 protein amount in the medium was determined with a human IL-6 Uncoated enzyme-linked immunosorbent assay (ELISA) kit (88-7066-22, Thermo Fisher Scientific).

Western blot analysis. Cells were washed with phosphate-buffered saline (PBS) 5 times and total protein was extracted with RIPA lysis buffer containing protease inhibitor cocktail. The protein amount in the extract was determined with the Pierce BCA Protein Assay kit (23225, Thermo Fisher Scientific) with bovine serum albumin (BSA, A7030, Sigma) as a standard. The protein extract $(10 \mu \mathrm{g})$ was denatured by the addition of sample buffer [5\% sodium dodecyl sulfate, $12.5 \%$ glycerol and $50 \mathrm{mM}$ dithiothreitol in $100 \mathrm{mM}$ Tris-hydrochloric acid ( $\mathrm{HCl}$ ) buffer, $\mathrm{pH}$ 6.8], and was heated at $95^{\circ} \mathrm{C}$ for $5 \mathrm{~min}$. The samples were separated by electrophoresis and were blotted onto a nitrocellulose membrane (1620090, Bio-Rad). The blotted membrane was blocked with 5\% non-fat dry milk (999S, Cell Signaling Technology) in Tris-buffered saline (TBS)-T buffer $(0.1 \%$ Tween-20, $\mathrm{pH}$ 7.6) for $1 \mathrm{~h}$, and was subsequently incubated in the presence of the rabbit anti-ICAM-1 (4915S, Cell Signaling Technology), anti-NF-кB (sc-109X, Santa Cruz Biotechnology) or anti-phosphorylated NF- $\mathrm{B}$ (3033, Cell Signaling Technology) antibody at a 1:2,000 dilution overnight at $4^{\circ} \mathrm{C}$. The membrane was washed 3 times and incubated in the presence of the HRP-conjugated anti-rabbit IgG antibody (7074S, Cell Signaling Technology) for $1 \mathrm{~h}$ at room temperature. On the other hand, another blotted membrane was incubated with the HRP-conjugated anti- $\beta$-actin antibody (PM053-7, MBL Life science) at a 1:2,000 dilution for $1 \mathrm{~h}$ at room temperature, in order to quantitatively normalize the immunoreactive ICAM-1 protein levels. After washing, immunoreactive proteins on the nitrocellulose membrane were visualized with Armasham ECL Prime peroxidase solution (RPN2232V, GE Healthcare), by using a luminoimage analyzer (ChemiDoc ${ }^{\mathrm{TM}}$ MP, Bio-Rad). The density of each immunoreactive band was analyzed with Image $\mathrm{Lab}^{\mathrm{TM}}$ software ver. 4.1 (Bio-Rad).

Reverse transcription-quantitative polymerase chain reaction $(R T-q P C R)$. Total RNA was isolated from cells with TRIzol reagent. Contaminated genomic DNA in the total RNA was removed by incubation with gDNA eraser (RR047A, Takara) 
A

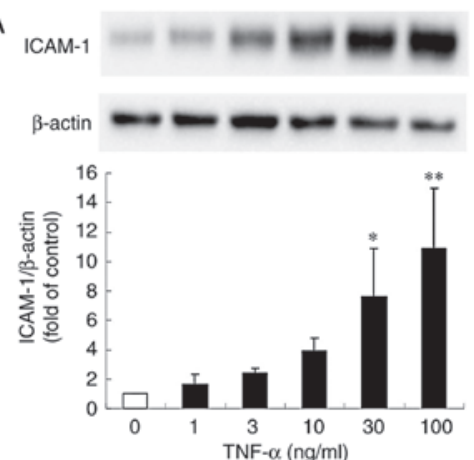

C
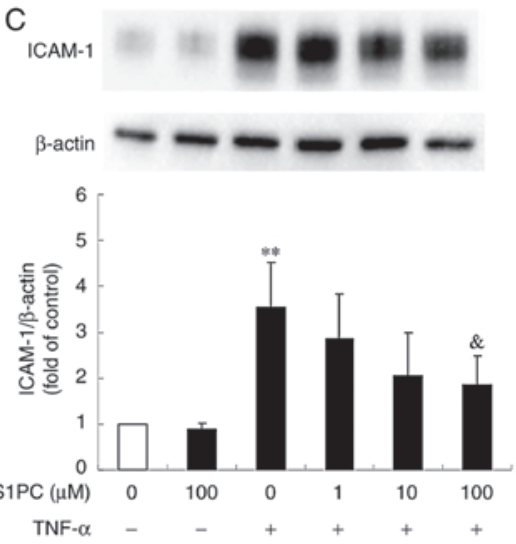

E
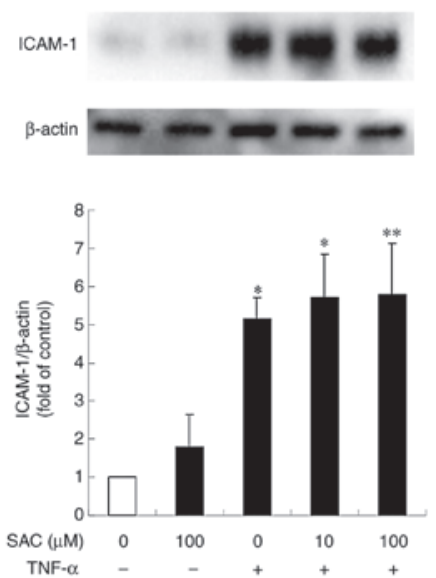

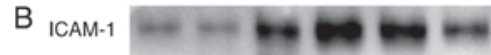

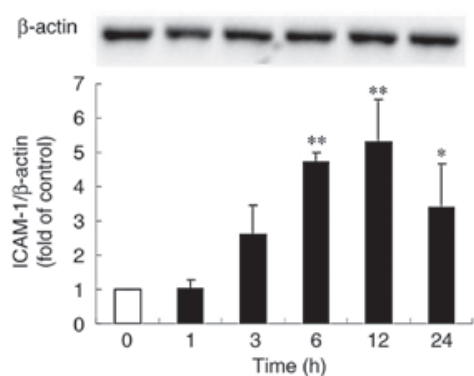

D
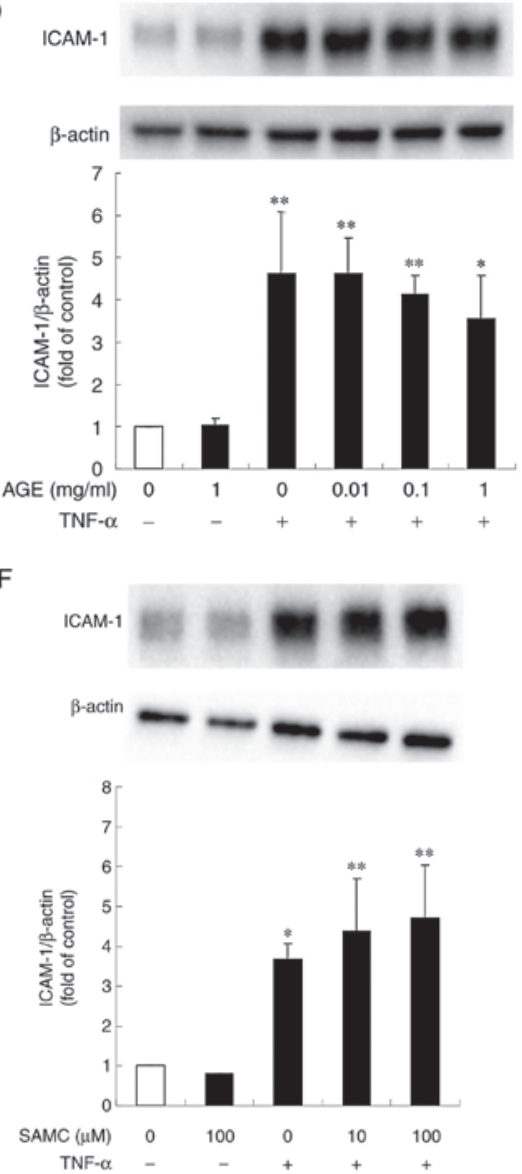

G
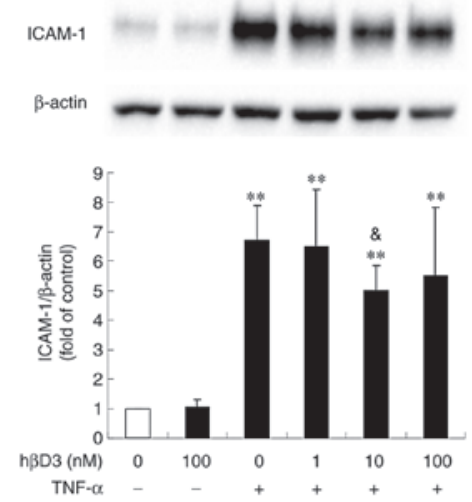

Figure 1. Effect of S1PC and h $\beta D 3$ on the level of ICAM-1 protein induced by TNF- $\alpha$. (A) The concentration (1 to $100 \mathrm{ng} / \mathrm{ml}, 12 \mathrm{~h}$ )- and (B) time (1 to $24 \mathrm{~h}$, $100 \mathrm{ng} / \mathrm{ml}$ )-dependent induction of ICAM-1 protein stimulated by TNF- $\alpha$. The cells were left untreated (control) or treated with TNF- $\alpha$ in the absence or presence of (C) S1PC (1 to $100 \mu \mathrm{M})$, (D) AGE (0.01 to $1 \mathrm{mg} / \mathrm{ml})$, (E) SAC $(10,100 \mu \mathrm{M})$, (F) SAMC $(10,100 \mu \mathrm{M})$ or $(\mathrm{G}) \mathrm{h} \beta \mathrm{D} 3(1 \mathrm{to} 100 \mathrm{nM})$ for $24 \mathrm{~h}$ and total protein was extracted. ICAM-1 proteins in the extract were detected by western blot analysis. Each bar in the graphs represents the mean \pm SD of the band intensity relative to $\beta$-actin $(\mathrm{n}=3)$. ${ }^{*} \mathrm{P}<0.05,{ }^{* *} \mathrm{P}<0.01$ in comparison to the control (Tukey's multiple comparison test). ${ }^{\text {\& }} \mathrm{P}<0.05$ in comparison to TNF- $\alpha$ alone (Student's t-test). S1PC, $S$-1-propenylcysteine; $\mathrm{h} \beta \mathrm{D} 3$, human $\beta$-defensin-3; TNF- $\alpha$, tumor necrosis factor- $\alpha$; ICAM-1, intercellular adhesion molecule-1; AGE, aged garlic extract; SAC, $S$-allylcysteine; SAMC, $S$-allylmercaptocysteine. 
for 5 min at room temperature, and total RNA was reverse transcribed into complementary DNA (cDNA) with a PrimeScript RT reagent kit with genomic DNA Eraser (RR047A, Takara). cDNA was amplified with primer pairs using a SYBR Premix Ex Taq II (RR820A, Takara). The level of gene expression relative to the internal control ( $\beta$-actin) was calculated by performing a quantitative (real-time) PCR with a Real-time PCR system (PikoReal 96, Life Technologies; Thermo Fisher Scientific). The reaction was run using the following program: $30 \mathrm{sec}$ at $95^{\circ} \mathrm{C}, 40$ repeats of $10 \mathrm{sec}$ at $95^{\circ} \mathrm{C}, 10 \mathrm{sec}$ of $63^{\circ} \mathrm{C}$ and $15 \mathrm{sec}$ of $72^{\circ} \mathrm{C}$. The sequences of the specific primers were as follows: human ICAM-1 forward, 5'-TCGGCACAAAA GCACTATATG-3' and reverse, 5'-ACAGGACAAGAGGAC AAGGC-3'; human IL-6 forward, 5'-TCTCCACAAGCGCCT T-3' and reverse, 5'-CTCAGGGCTGAGATGC-3'; and $\beta$-actin forward, 5'-CGCGAGAAGATGACCCAGAT-3' and reverse, 5'-GGTGAGGATCTTCATGAGGTAGTC-3'. The fold change in the relative mRNA level to $\beta$-actin was calculated based on the $\mathrm{Cq}(\Delta \Delta \mathrm{Cq})$ method (20).

Cellular IL-6 protein content. Following treatment of the cells with TNF- $\alpha(100 \mathrm{ng} / \mathrm{ml})$ in the absence or presence of AGE $(1 \mathrm{mg} / \mathrm{ml})$ or SAC $(100 \mu \mathrm{M})$ for $3 \mathrm{~h}$, the total protein was extracted with RIPA buffer. The amount of IL- 6 protein in the extract was determined by ELISA, as described above. The cellular IL-6 protein content is expressed relative to $1 \mathrm{mg}$ total protein.

Statistical analysis. Data are expressed as the means \pm standard deviation (SD). Statistical significance was evaluated using the Student's t-test for differences between 2 groups or one-way analysis of variance (ANOVA), followed by Tukey's post hoc test for differences between $>3$ groups. A P-value $<0.05$ was statistically significant in comparison to control or the effect of TNF- $\alpha$ alone.

\section{Results}

Effect of S1PC and $h \beta D 3$ on the level of ICAM-1 protein induced by $T N F-\alpha$. Human gingival fibroblasts and Ca9-22 cells have been shown to express ICAM-1 in response to the periodontal disease bacteria, P.g.-derived LPS or TNF- $\alpha$ (21-25). It was also found that ICAM-1 protein expression in the Ca9-22 cells was profoundly induced by treatment with TNF- $\alpha$ in a concentration-dependent manner (Fig. 1A). In addition, the ICAM-1 protein level began to increase at $3 \mathrm{~h}$, reached peak levels at $12 \mathrm{~h}$ and remained elevated until $24 \mathrm{~h}$ (Fig. 1B). As shown in Fig. 1C, the presence of S1PC for $24 \mathrm{~h}$ inhibited the increased level of TNF- $\alpha$-induced ICAM-1 protein in a concentration-dependent manner, whereas treatment with AGE exerted minimal inhibitory effects even at the highest concentration (1 mg/ml) (Fig. 1D). Both SAC and SAMC also had no significant effect (Fig. 1E and F).

It has been previously demonstrated that the anti-microbial peptide $\mathrm{h} \beta \mathrm{D} 3$ reduces the level of TNF- $\alpha$-elicited ICAM-1 protein in human vein endothelial cells (HUVECs) (26). Thus, this study examined whether the peptide inhibits the level of ICAM-1 protein in Ca9-22 cells. As shown in Fig. 1G, the increased level of TNF- $\alpha$-induced ICAM-1 protein was moderately but significantly suppressed by $\mathrm{h} \beta \mathrm{D} 3$ at $10 \mathrm{nM}$,
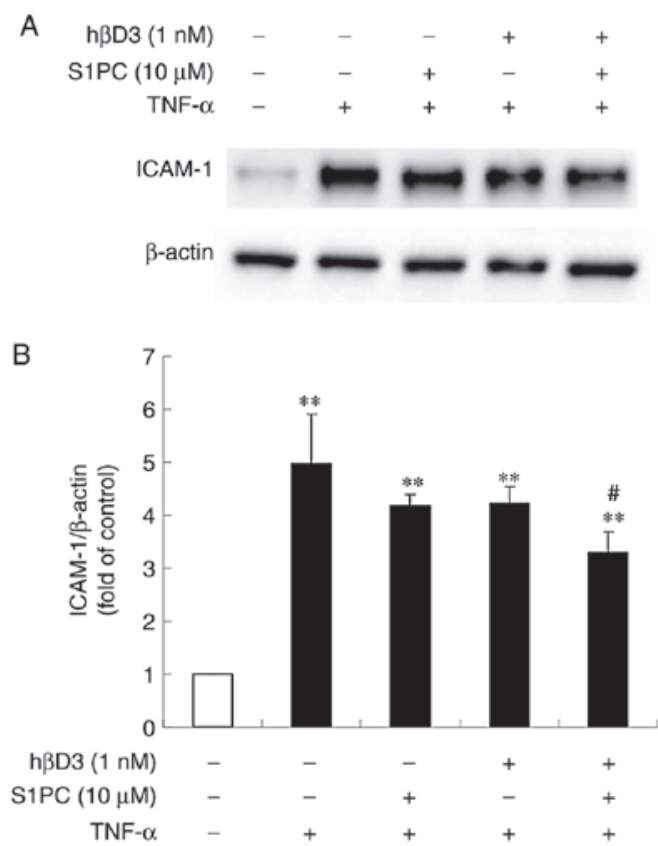

Figure 2. Effect of S1PC on the level of ICAM-1 protein induced by TNF- $\alpha$ in the presence of $\mathrm{h} \beta \mathrm{D} 3$. (A) The cells were left untreated (control) or treated with TNF- $\alpha(100 \mathrm{ng} / \mathrm{ml})$ in the absence or presence of S1PC $(10 \mu \mathrm{M})$ and/or

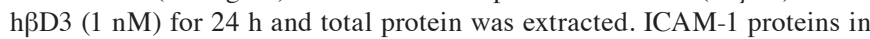
the extract were detected by western blot analysis. (B) Quantitative analysis of the band intensity relative to $\beta$-actin. Each bar in the graph represents the mean $\pm \mathrm{SD}(\mathrm{n}=3) .{ }^{* *} \mathrm{P}<0.01$ in comparison to the control and ${ }^{*} \mathrm{P}<0.05$ in comparison to TNF- $\alpha$ alone (Tukey's multiple comparisons test). S1PC, $S$-1-propenylcysteine; h $\beta \mathrm{D} 3$, human $\beta$-defensin-3; TNF- $\alpha$, tumor necrosis factor- $\alpha$; ICAM-1, intercellular adhesion molecule-1.

indicating that this peptide is also effective. Furthermore, it was found that the inhibitory effect of $h \beta D 3$ was enhanced by simultaneously treating the cells in the presence of S1PC (Fig. 2), suggesting the synergistic effect of $\mathrm{h} \beta \mathrm{D} 3$ and S1PC.

Effect of h $\beta D 3$ and S1PC on ICAM-1 gene expression induced by $T N F-\alpha$. It is conceivable that the inhibitory effect of S1PC on the level of ICAM-1 protein was due to the suppression of ICAM-1 gene transcriptions. Thus, this study then examined the effects of S1PC as well as those of $\mathrm{h} \beta \mathrm{D} 3$ over a period of 3 or $24 \mathrm{~h}$ treatment on the TNF- $\alpha$-induced ICAM-1 gene expression by RT-qPCR. As shown in Fig. 3A, TNF- $\alpha$ significantly enhanced the basal ICAM-1 mRNA transcription level with a peak at $3 \mathrm{~h}$. Treatment with S1PC or hbD3 for either 3 or $24 \mathrm{~h}$ had no effect on the mRNA expression level of ICAM-1 increased by TNF- $\alpha$ (Fig. 3B and C). These results suggested that the actions of S1PC and h $\beta \mathrm{D} 3$ occurred at the post-transcriptional level, since these compounds did not affect ICAM-1 expression even at the concentrations at which induced a decrease in the protein level.

Effect of S1PC on the level of ICAM-1 protein induced by $T N F-\alpha$ in the presence of cycloheximide (CHX). Since S1PC did not affect ICAM-1 gene expression, we then examined their effect at the translational level using $\mathrm{CHX}$, an inhibitor of protein synthesis. As shown in Fig. 4, the inhibitory effects of CHX on the protein level of ICAM-1 were enhanced in the presence of S1PC in cells treated with TNF- $\alpha$. This result suggested that the effects of S1PC occurred at the 

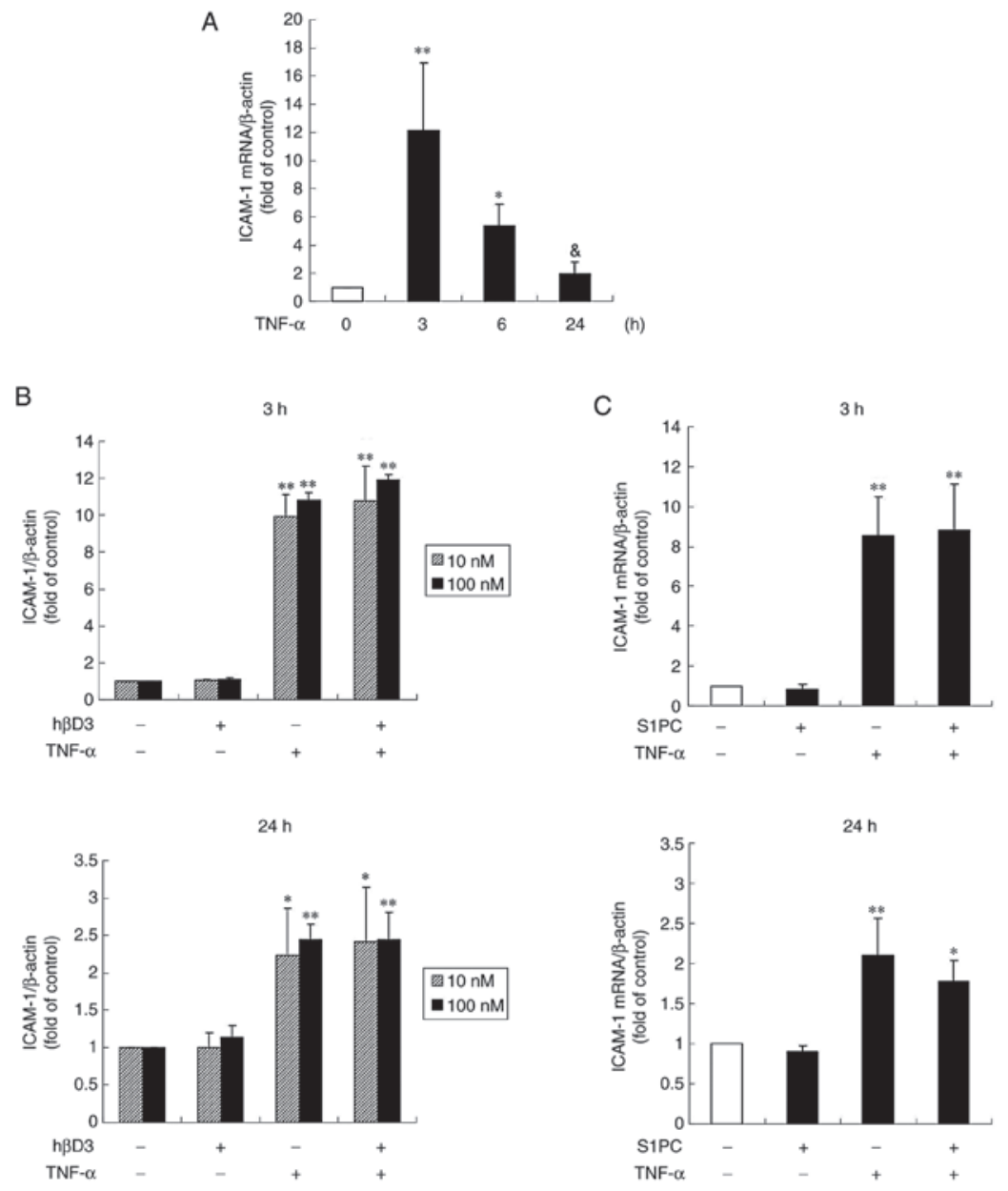

Figure 3. Effect of $\mathrm{h} \beta \mathrm{D} 3$ and S1PC on the ICAM-1 gene expression induced by TNF- $\alpha$. The cells were untreated (control) or treated with (A) TNF- $\alpha$ (100 ng/ml) alone for 3,6 or $24 \mathrm{~h}$ or in the presence of $(\mathrm{B}) \mathrm{h} \beta \mathrm{D} 3(10,100 \mathrm{nM})$ or $(\mathrm{C}) \mathrm{S} 1 \mathrm{PC}(100 \mu \mathrm{M})$ for $3 \mathrm{~h}$ or $24 \mathrm{~h}$, and total RNA was extracted. The ICAM-1 mRNA expression level in total RNA was evaluated by RT-qPCR. Each bar in graphs represents the mean $\pm \mathrm{SD}(\mathrm{n}=3-5)$. ${ }^{*} \mathrm{P}<0.05,{ }^{* *} \mathrm{P}<0.01$ (Tukey's multiple comparison test) or ${ }^{\&} \mathrm{P}<0.05$ (Student's $\mathrm{t}$-test) in comparison to the control. S1PC, $S$-1-propenylcysteine; $\mathrm{h} \beta \mathrm{D} 3$, human $\beta$-defensin-3; TNF- $\alpha$, tumor necrosis factor- $\alpha$; ICAM-1, intercellular adhesion molecule-1 .

A

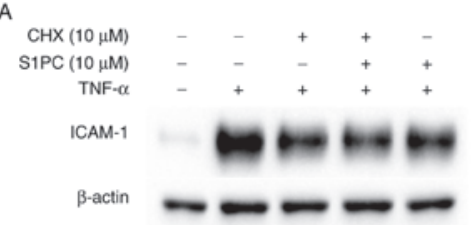

B

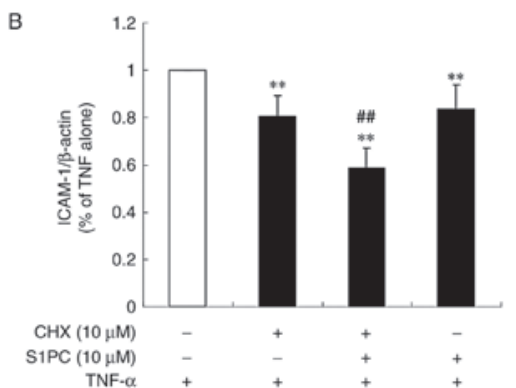

Figure 4. Effect of S1PC on the level of ICAM-1 protein induced by TNF- $\alpha$ in the presence of cycloheximide (CHX). (A) The cells were left untreated (control) or pretreated with TNF- $\alpha(100 \mathrm{ng} / \mathrm{ml})$ for $12 \mathrm{~h}$ in the absence or presence of CHX $(10 \mu \mathrm{M})$ and/or S1PC $(10 \mu \mathrm{M})$ for $6 \mathrm{~h}$ and total protein was extracted. ICAM-1 proteins in the extract were detected by western blot analysis. (B) The quantitative analysis of the band intensity relative to $\beta$-actin. Each bar in the graph represents the mean $\pm \mathrm{SD}(\mathrm{n}=3) .{ }^{* *} \mathrm{P}<0.01$ in comparison to control and ${ }^{\# \#} \mathrm{P}<0.01$ in comparison to TNF- $\alpha$ alone (Tukey's multiple comparisons test). S1PC, $S$-1-propenylcysteine; $\mathrm{h} \beta \mathrm{D} 3$, human $\beta$-defensin-3; TNF- $\alpha$, tumor necrosis factor- $\alpha$; ICAM-1, intercellular adhesion molecule-1. post-translational level, since this compound induced a further reduction in the ICAM-1 protein level when total protein synthesis was blocked.

Effect of AGE, SAC and SAMC on IL-6 secretion induced by $T N F-\alpha$. IL- 6 is produced in human gingival epithelial cells in response to LPS or TNF- $\alpha$, leading to the activation of osteoclasts via the upregulation of receptor activator of $N F-\kappa B$ ligand (RANKL) in osteoblasts (21). This study thus examined the effects of TNF- $\alpha$ on IL-6 secretion in Ca9-22 cells. As shown in Fig. 5A, TNF- $\alpha$ stimulated basal IL- 6 secretion during $6 \mathrm{~h}$ of culture. The enhanced IL- 6 secretion induced by TNF- $\alpha$ was reduced by simultaneous treatment with AGE, SAC or SAMC in a concentration-dependent manner (Fig. 5A-C). On the other hand, S1PC had no effect on IL-6 secretion even at the concentration of $100 \mu \mathrm{M}$ (Fig. 5D).

Effect of AGE, SAC and SAMC on IL-6 gene expression induced by $T N F-\alpha$. It was possible that SAC and SAMC downregulated IL- 6 gene transcription induced by TNF- $\alpha$. Thus, the effecto of these sulfur compounds on the IL-6 gene expression level were then examined by RT-qPCR. It was found that TNF- $\alpha$ significantly enhanced the basal IL-6 mRNA transcription level with a peak at $3 \mathrm{~h}$ (Fig. 6A). As 
A

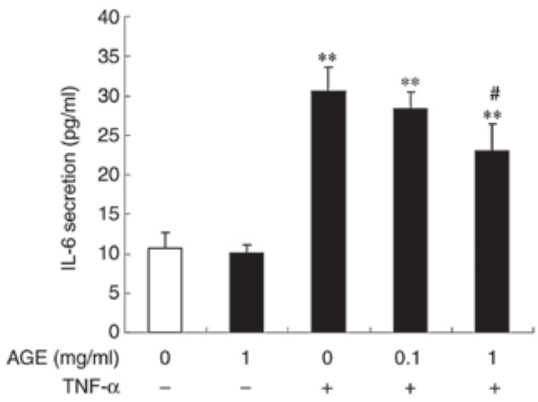

$\mathrm{C}$

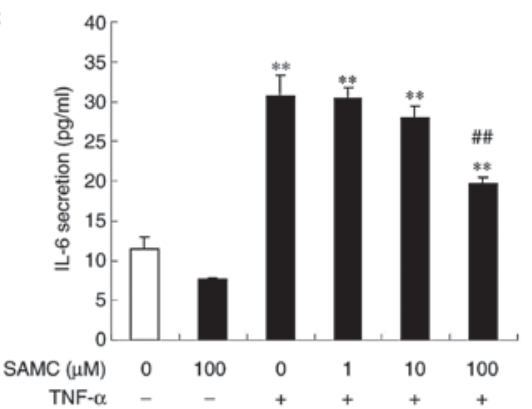

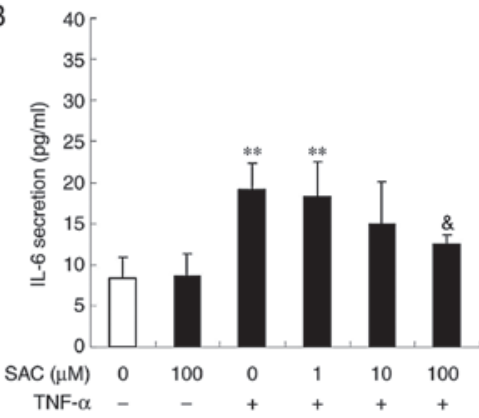

D

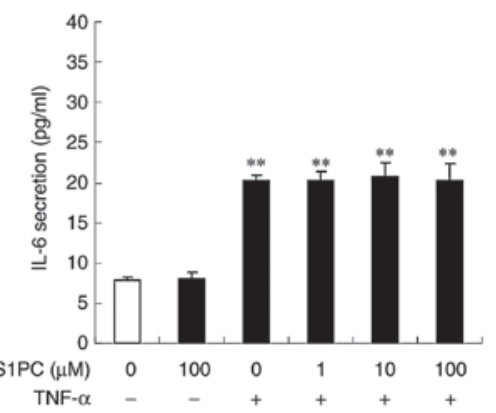

Figure 5. Effect of AGE, SAC and SAMC on IL-6 secretion induced by TNF- $\alpha$. The cells were left untreated (control) or treated with TNF- $\alpha$ (100 ng/ml) in the absence or presence of (A) AGE, (B) SAC, (C) SAMC or (D) S1PC (each at 1 to $100 \mu \mathrm{M}$ ) for $6 \mathrm{~h}$ and culture medium was collected. The IL-6 concentration in the medium was determined by ELISA. Each bar in graphs represents the mean $\pm \mathrm{SD}(\mathrm{n}=3-4)$. ${ }^{\text {** }} \mathrm{P}<0.01$ in comparison to the control and ${ }^{\#} \mathrm{P}<0.05$, ${ }^{\# \#} \mathrm{P}<0.01$ (Tukey's multiple comparison test), ${ }^{\circledR} \mathrm{P}<0.05$ in comparison to TNF- $\alpha$ alone (Student's t-test). S1PC, $S$-1-propenylcysteine; h $\beta$ D3, human $\beta$-defensin-3; TNF- $\alpha$, tumor necrosis factor- $\alpha$; IL-6, interleukin-6; AGE, aged garlic extract; SAC, $S$-allylcysteine; SAMC, $S$-allylmercaptocysteine.

A

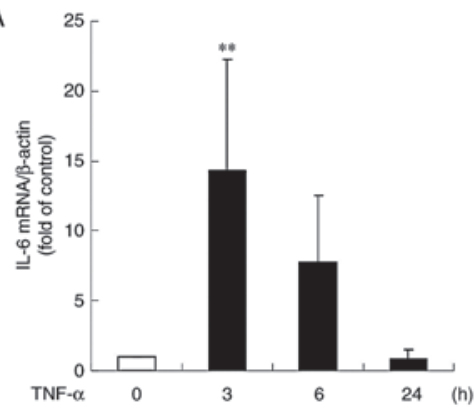

C

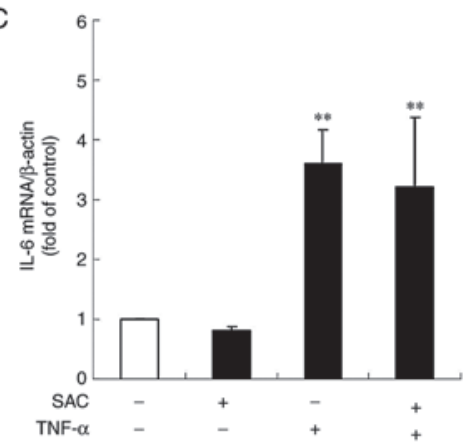

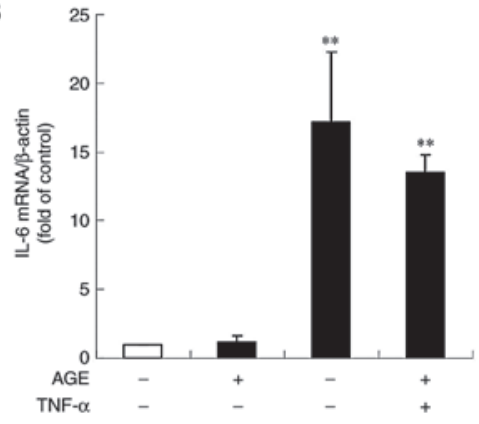

D

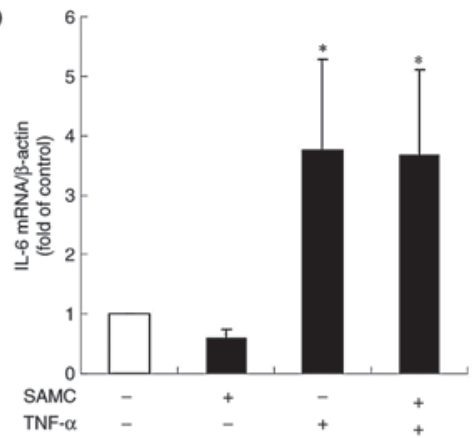

Figure 6. Effect of AGE, SAC and SAMC on the IL-6 gene expression induced by TNF- $\alpha$. The cells were untreated (control) or treated with (A) TNF- $\alpha$ $(100 \mathrm{ng} / \mathrm{ml})$ alone for 3,6 or $24 \mathrm{~h}$ or in the presence of (B) AGE $(1 \mathrm{mg} / \mathrm{ml}$ ) or (B) SAC, (C) SAC, (D) SAMC (each at $100 \mu \mathrm{M}$ ) for $3 \mathrm{~h}$ and total RNA was extracted. The IL-6 mRNA expression level in total RNA was evaluated by RT-qPCR. Each bar in graphs represents the mean \pm SD $(n=3-6)$. "P<0.05, ${ }^{* *} \mathrm{P}<0.01$ (Tukey's multiple comparison test) in comparison to the control. S1PC, $S$-1-propenylcysteine; $\mathrm{h} \beta \mathrm{D} 3$, human $\beta$-defensin-3; TNF- $\alpha$, tumor necrosis factor- $\alpha$; IL-6, interleukin-6; AGE, aged garlic extract; SAC, S-allylcysteine; SAMC, $S$-allylmercaptocysteine.

shown in Fig. 6B-D, treatment with AGE, SAC or SAMC for $3 \mathrm{~h}$ had a minimal effect on the enhanced IL- 6 mRNA expression level induced by TNF- $\alpha$.
Effect of AGE, SAC and SAMC on the intracellular IL-6 protein content. In order to examine whether AGE and sulfur compounds affect the IL-6 secretion process, the cellular IL-6 

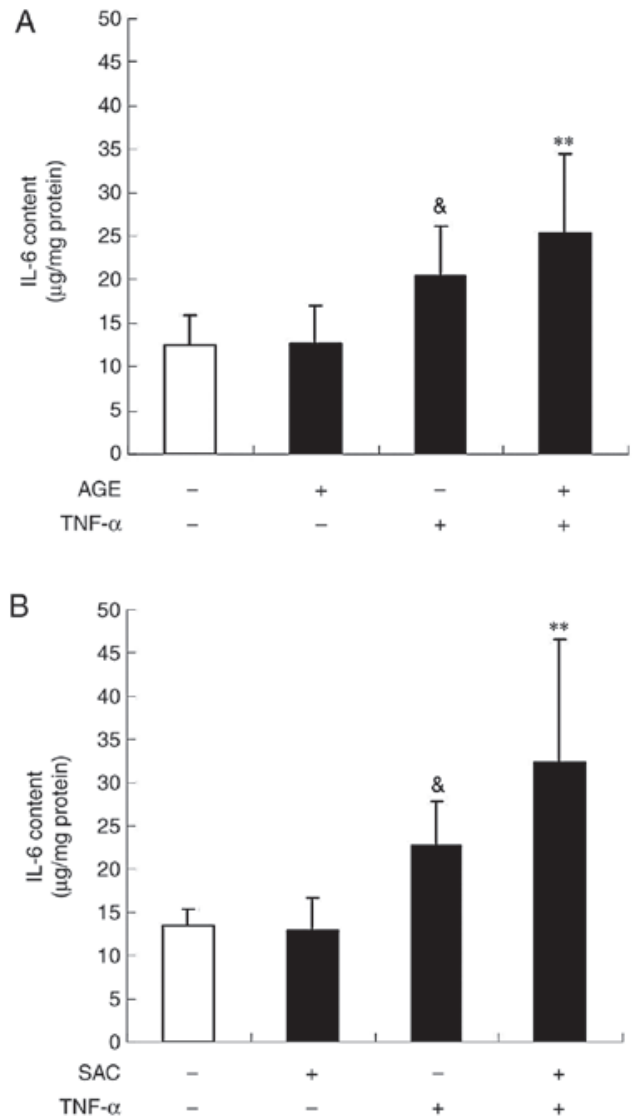

Figure 7. Effect of AGE and SAC on the intracellular IL-6 content induced by TNF- $\alpha$. The cells were left untreated (control) or treated with TNF- $\alpha$ $(100 \mathrm{ng} / \mathrm{ml})$ in the absence or presence of (A) AGE or (B) SAC $(100 \mu \mathrm{M})$ for $3 \mathrm{~h}$ and total protein was extracted. The IL- 6 content in the protein extract was determined by ELISA. Each bar in the graphs represents the mean \pm SD $(\mathrm{n}=6) .{ }^{* *} \mathrm{P}<0.01$ (Tukey's multiple comparison test), ${ }^{\circledR} \mathrm{P}<0.05$ (Student's t-test) in comparison to the control. TNF- $\alpha$, tumor necrosis factor- $\alpha$; IL-6, interleukin-6; AGE, aged garlic extract; SAC, S-allylcysteine.

protein content was measured during TNF- $\alpha$ stimulation by ELISA. Treatment with AGE $(1 \mathrm{mg} / \mathrm{ml})$ or SAC $(100 \mu \mathrm{M})$ for $3 \mathrm{~h}$ exhibited a tendency to enhance the effects of TNF- $\alpha$ on the cellular IL-6 content, although their effects were not statistically significant (Fig. 7).

Effect of $h \beta D 3, S 1 P C, A G E, S A C$ and SAMC on the level of phosphorylated NFkB p65 protein induced by TNF- $\alpha$. Stimulation of the cells with TNF- $\alpha$ has been shown to activate a variety of signaling pathways and transcription factors, such as NF- $\mathrm{NB}$, which plays an essential role in the expression of inflammation-related molecules (26-28). In addition, h $\beta \mathrm{D} 3$ has been shown to alleviate periodontitis via the suppression of NF- $\kappa B$ (29). Thus, this study examined the effects of $\mathrm{h} \beta \mathrm{D} 3, \mathrm{~S} 1 \mathrm{PC}, \mathrm{AGE}, \mathrm{SAC}$ and SAMC on the phosphorylation (activation) of NF- $\mathrm{NB}$ induced by TNF- $\alpha$. As shown in Fig. 8A and C-E, h $\beta \mathrm{D} 3$ (100 nM), AGE (1 mg/ml), SAC and SAMC (each at $100 \mu \mathrm{M}$ ) inhibited $\mathrm{NF}-\kappa \mathrm{B}$ activation, whereas S1PC $(100 \mu \mathrm{M})$ did not have any significant effect (Fig. 8B).

\section{Discussion}

In gingivitis and periodontitis, TNF- $\alpha$ secreted from macrophages and neutrophils accumulates in gingival tissues during the progression of inflammation and induces cytokine production, such as IL-6 in gingival cells, leading to an increased RANKL expression in osteoblasts, the activation of osteoclasts and consequently, to the resorption of alveolar bone (30). Therefore, regulating the excess inflammation in gingiva is considered to be a key step to treat the periodontal diseases. In the present study, it was found that sulfur-containing compounds in AGE differentially inhibited the TNF- $\alpha$-elicited ICAM-1 expression and IL-6 secretion, suggesting that these compounds control inflammation occurring in human gingival tissues under pathological conditions such as gingivitis.

ICAM-1 is expressed by several cell types in response to a variety of stimuli, such as LPS and pro-inflammatory cytokines, and helps to bind lymphocytes to $\mathrm{T}$ cells or vascular endothelial cells, leading to the activation of immune responses and the trans-endothelial migration of lymphocytes $(31,32)$. It has been demonstrated that ICAM-1 is highly expressed in inflamed tissues, such as atherosclerotic lesions and is associated with disease progression (32). There are a number of findings indicating that ICAM-1 is highly expressed by treating HUVECs with TNF- $\alpha$ or LPS (33-35). Zhao et al demonstrated that a variety of intracellular signaling molecules, such as p38 MAPK acting on the MAPK pathway, nicotinamide adenine dinucleotide phosphate (NADPH) oxidase and the transcription factor $\mathrm{NF}-\kappa \mathrm{B}$, were involved in the ICAM-1 expression in HUVEC (35). In particular, $N F-\kappa B$ plays a crucial role in innate immune responses via enhanced transcription of inflammatory mediators, including interleukins, chemokines and cytokines $(27,28)$. The findings of study suggest that S1PC can modulate the level of ICAM-1 protein in Ca9-22 cells independently of $\mathrm{NF}-\kappa \mathrm{B}$. At present, the S1PC-mediated intracellular pathway remains to be elucidated.

In human gingival fibroblast cells, ICAM-1 is expressed in response to pro-inflammatory cytokines, such as TNF- $\alpha$ and IL-1 $\beta(21,22)$ or periodontal pathogens such as $P$. gingivalis (23) via the activation of $\mathrm{NF}-\kappa \mathrm{B}, \mathrm{p} 38 \mathrm{MAPK}$ or nucleotide binding oligomerization domain-containing protein (NOD). On the other hand, to the best of our knowledge, there are only a few studies available to date demonstrating the TNF- $\alpha$-induced expression of ICAM-1 in human gingival epithelial cells, particularly Ca9-22 cells $(22,25)$, and the functional mechanisms have not yet been fully clarified. However, it was previously demonstrated that TNF- $\alpha$ also enhanced the expression or secretion of IL-6 and IL-8 proteins in another human gingival epithelial cell line (OBA9) (36) and the oral epithelial cell line, TR146 (37). These findings indicate that Ca9-22 cells are also available to pharmacologically investigate the anti-inflammatory function of AGE, although Ca9-22 cells have been often used as an oral cancer model. Thus, this study first examined whether TNF- $\alpha$ induces the ICAM-1 expression and found that the levels of both ICAM-1 protein and mRNA were augmented by TNF- $\alpha$, but only slightly by $P$.g.-derived LPS, indicating that Ca9-22 cells were less sensitive to LPS. It was also found that S1PC inhibited the level of TNF- $\alpha$-induced ICAM-1 protein possibly through post-translational modification (Fig. 4), while AGE caused little inhibition, suggesting that AGE may contain some substances to block the S1PC action. Furthermore, it was shown that extracellular signal-regulated kinase-1/2 (ERK1/2), p38 MAPK (data not shown) and NF- $\kappa$ B (Fig. 8B) were not involved in the inhibition by S1PC. 
A

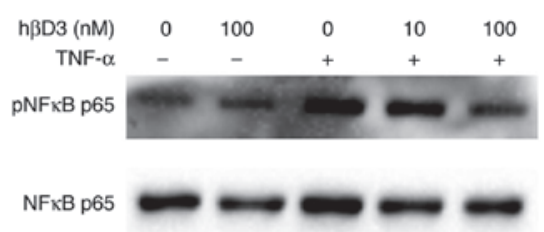

B

C
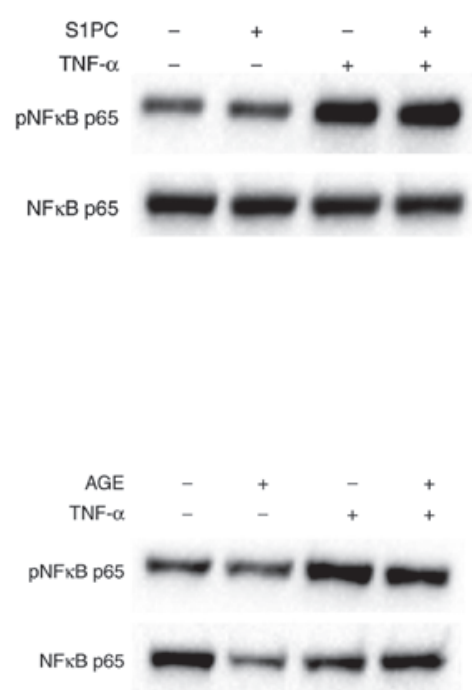

D

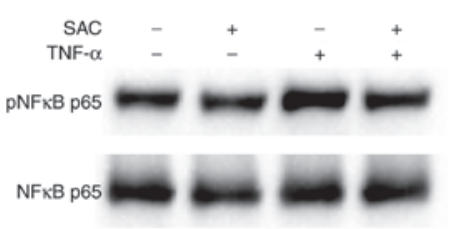

$\mathrm{E}$

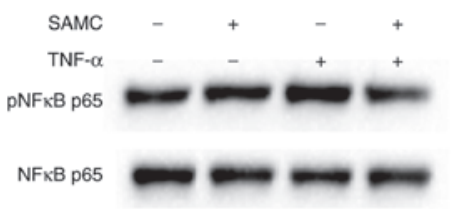

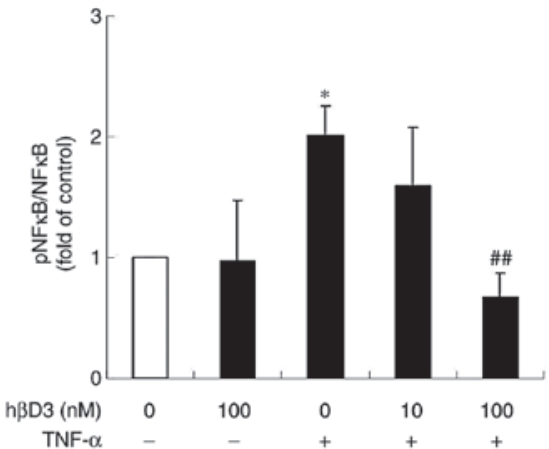
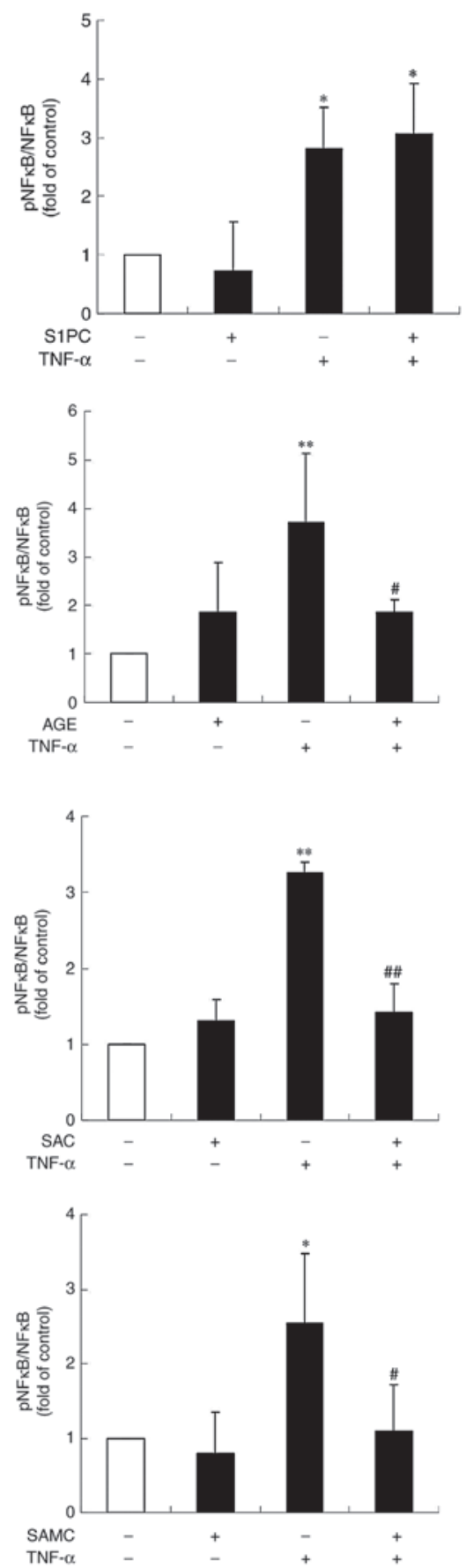

Figure 8. Effect of $\mathrm{h} \beta \mathrm{D} 3, \mathrm{~S} 1 \mathrm{PC}, \mathrm{AGE}, \mathrm{SAC}$ and SAMC on the level of phosphorylated NF- $\mathrm{BB}$ p65 protein induced by TNF- $\alpha$. The cells were left untreated (control) or treated with TNF- $\alpha(100 \mathrm{ng} / \mathrm{ml})$ in the absence or presence of (A) h $\beta \mathrm{D} 3(10,100 \mathrm{nM}$ ) or (B) S1PC (100 $\mu \mathrm{M})$ for $24 \mathrm{~h}$, (C) AGE (1 mg/ml), (D) SAC

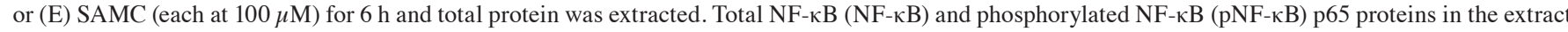
were detected by western blot analysis. Each bar in graphs represents the mean $\pm \mathrm{SD}$ of the band intensity relative to $\beta$-actin $(\mathrm{n}=3-4)$. ${ }^{*} \mathrm{P}<0.05$, ${ }^{* * *} \mathrm{P}<0.01$ in comparison to the control and ${ }^{\#} \mathrm{P}<0.05,{ }^{\# \#} \mathrm{P}<0.01$ in comparison to TNF- $\alpha$ alone (Tukey's multiple comparisons test). S1PC, $S$-1-propenylcysteine; h $\beta \mathrm{D} 3$, human $\beta$-defensin-3; TNF- $\alpha$, tumor necrosis factor- $\alpha$; IL-6, interleukin-6; AGE, aged garlic extract; SAC, $S$-allylcysteine; SAMC, $S$-allylmercaptocysteine. 
The antimicrobial peptide, $\mathrm{h} \beta \mathrm{D} 3$, is mainly produced in gingival epithelial cells and is extracellularly secreted into the oral cavity, and exhibits antimicrobial activity against Gram-positive and negative bacteria, fungi and viruses $(29,38)$. $\mathrm{h} \beta \mathrm{D} 3$ also plays an important role in the innate immune response via its immunomodulatory effect, suppressing the periodontal diseases progression $(29,38)$. It has been reported that the $\mathrm{h} \beta \mathrm{D} 3$ expression level in gingival tissues and crevicular fluid is decreased in patients with periodontitis in comparison to healthy controls (29). It has been found that $h \beta D 3$ reduced the level of ICAM-1 protein and inhibits the phosphorylation of NF- $\kappa \mathrm{B}$ induced by TNF- $\alpha$, which is consistent with a finding obtained in HUVECs (26). Although it was not statistically significant, S1PC at $10 \mu \mathrm{M}$ exhibited near the maximal inhibition induced by S1PC at $100 \mu \mathrm{M}$ on the elevated ICAM-1 protein by TNF- $\alpha$ (Fig. 1C). Similarly, $\mathrm{h} \beta \mathrm{D} 3$ exhibited the maximal inhibition at $10 \mathrm{nM}$ (Fig. 1G). Since it seemed to be difficult to detect further inhibition when S1PC and h $\beta \mathrm{D} 3$ at the higher concentrations, such as $100 \mu \mathrm{M}$ and $10 \mathrm{nM}$, respectively, are used, the authors used $\mathrm{S} 1 \mathrm{PC}$ at $10 \mu \mathrm{M}$ and $\mathrm{h} \beta \mathrm{D} 3$ at $1 \mathrm{nM}$ in the synergistic experiment. As shown in Fig. 2, it was found that the inhibitory effect of $h \beta D 3$ was enhanced by simultaneous treatment with S1PC, suggesting that S1PC synergistically modulates the action of $\mathrm{h} \beta \mathrm{D} 3$ through a signaling pathway different from that of this peptide.

IL-6 is transiently produced and secreted by several cell types in response to infections and tissue injuries under acute inflammation (39). It was well known that IL-6 exerts beneficial pleiotropic effects, i.e., the maturation of B cells into antibody-producing cells and development of effector T-cells (39). On the other hand, the continuous production of IL-6 in inflamed tissues results in the progression of chronic inflammation and autoimmunity (39). Thus, the precise control of IL-6 secretion is crucial to prevent severe inflammation, which is often observed under pathophysiological conditions, including rheumatoid arthritis (39).

In human gingival fibroblasts, the pro-inflammatory cytokine, IL-1 $\beta$, secreted from macrophages promotes the production and secretion of IL-6 (40). IL-6 facilitates inflammation at higher concentrations via the activation of matrix metalloproteases (MMPs) and osteoclasts, resulting in the gingival tissue destruction and alveolar bone resorption (40). In human gingival epithelial OBA9 cells, the IL-6 mRNA level has been shown to be augmented by stimulation with TNF- $\alpha$ through the phosphorylation of ERK1/2 and p38 MAPK (36). This study found that the enhanced IL-6 secretion by $\mathrm{Ca} 9-22$ cells stimulated with $\mathrm{TNF}-\alpha$ was significantly inhibited by simultaneously treating the cells with AGE, SAC or SAMC, suggesting their involvement in the regulation of IL- 6 secretion. However, these substances did not exhibit any inhibitory effect on the IL- 6 mRNA expression levels (Fig. 6), suggesting the post-transcriptional mode of control. In addition, it was found that AGE and SAC tended to augment the content of IL- 6 protein in cells induced by TNF- $\alpha$, supporting their post-translational modifications. Based on these findings, it is possible that the reduced IL-6 release by AGE or SAC may result from the partial blockade of extracellular secretion, but not from the decreased production of the cytokine.
In conclusion, this study found that AGE and its sulfur compounds, S1PC, SAC and SAMC, inhibited inflammatory reactions induced by TNF- $\alpha$ in human gingival epithelial cells. Although their mechanisms of action have not been fully clarified, these data suggest that these sulfur compounds in AGE may directly reduce inflammation occurring in human gingival epithelial cells by suppressing the ICAM-1 expression and IL-6 secretion. Moreover, it is possible that the sulfur compounds in AGE ingested through systemic circulation reduced gingival inflammation to improve gingivitis.

\section{Acknowledgements}

The authors would like to thank Dr Takami Oka of Wakunaga Pharmaceutical Co., Ltd. for his helpful advice, encouragement and critical reading of the manuscript.

\section{Funding}

This study was funded by Wakunaga Pharmaceutical Co., Ltd.

\section{Availability data and materials}

All data generated or analyzed during this study are included in this published article or are available from the corresponding author on reasonable request.

\section{Authors' contributions}

MO drafted the manuscript and performed the experiments. TN proposed a part of the experimental ideas and concepts, helped interpret the data and revised the manuscript. Both authors have read and approved the final manuscript.

\section{Ethics approval and consent to participate}

Not applicable.

\section{Patient consent for publication}

Not applicable.

\section{Competing interests}

The authors declare that they have no competing interests.

\section{References}

1. Zini A, Mann J, Mazor S and Vered Y: The efficacy of aged garlic extract on gingivitis-A randomized clinical trial. J Clin Dentist 29: 52-56, 2018.

2. Sojod B, Chateau D, Mueller CG, Babajko S, Berdal A, Lézot F and Castaneda B: RANK/RANKL/OPG signalization implication in periodontitis: New evidence from a RANK transgenic mouse model. Front Physiol 8: 338, 2017.

3. Tzach-Nahman R, Nashef R, Fleisigg O, Palmon A, Shapira L, Wilensky A and Nussbaum G: Oral fibroblasts modulate the macrophage response to bacterial challenge. Sci Rep 7: 11516, 2017.

4. Wu YH, Kuraji R, Taya Y, Ito H and Numabe Y: Effects of theaflavins on tissue inflammation and bone resorption on experimental periodontitis in rats. J Periodontal Res 53: 1009-1019, 2018.

5. Morihara N, Hino A, Yamaguchi T and Suzuki JI: Aged garlic extract suppresses the development of atherosclerosis in apolipoprotein E-knockout mice. J Nutr 146: 460S-463S, 2016. 
6. Zeb I, Ahmadi N, Nasir K, Kadakia J, Larijani VN, Flores F, Li D and Budoff MJ: Aged garlic extract and coenzyme Q10 have favorable effect on inflammatory markers and coronary atherosclerosis progression: A randomized clinical trial. J Cardiovasc Dis Res 3: 185-190, 2012.

7. Matsutomo T, Ushijima M, Kodera $Y$, Nakamoto $M$, Takashima M, Morihara N and Tamura K: Metabolomic study on the antihypertensive effect of S-1-propenylcysteine in spontaneously hypertensive rats using liquid chromatography coupled with quadrupole-Orbitrap mass spectrometry. J Chromatogr B 1046: 147-155, 2017.

8. Ried K, Travica N and Sali A: The effect of aged garlic extract on blood pressure and other cardiovascular risk factors in uncontrolled hypertensives: The AGE at heart trial. Integr Blood Press Control 9: 9-21, 2016.

9. Suzuki JI, Kodera Y, Miki S, Ushijima M, Takashima M, Matsutomo T and Morihara N: Anti-inflammatory action of cysteine derivative $S$-1-propenylcysteine by inducing MyD88 degradation. Sci Rep 8: 14148, 2018.

10. Suzuki J, Yamaguchi T, Matsutomo T, Amano H, Morihara N and Kodera Y: S-1-Propenylcysteine promotes the differentiation of $\mathrm{B}$ cells into IgA-producing cells by the induction of Erk1/2-dependent Xbpl expression in Peyer's patches. Nutrition 32: 884-889, 2016.

11. Anandasadagopan SK, Sundaramoorthy C, Pandurangan AK Nagarajan V, Srinivasan K and Ganapasam S: S-Allyl cysteine alleviates inflammation by modulating the expression of NF- $\mathrm{BB}$ during chromium (VI)-induced hepatotoxicity in rats. Hum Exp Toxicol 36: 1186-1220, 2017.

12. Hiramatsu K, Tsuneyoshi T, Ogawa T and Morihara N: Aged garlic extract enhances heme oxygenase-1 and glutamate-cysteine ligase modifier subunit expression via the nuclear factor erythroid 2 -related factor 2-antioxidant response element signaling pathway in human endothelial cells. Nutr Res 36: 143-149, 2016.

13. Tsuneyoshi T, Kunimura K and Morihara N: $S$-1-Propenylcysteine augments BACH1 degradation and heme oxygenase 1 expression in a nitric oxide-dependent manner in endothelial cells. Nitric Oxide 84: 22-29, 2019.

14. Wang HH, Lee HM, Raja V, Hou W, Lacono VJ, Sacduto J, Johnson F, Golub MN and Gu Y: Enhanced efficacy of chemically modified curcumin in experimental periodontitis: Systemic implications. J Exp Pharmacol 11: 1-14, 2019.

15. Fu E, Tsai MC, Chin YT, Tu HP, Fu MM, Chian CY and Chiu HC: The effects of diallyl sulfide upon Porphyromonas gingivalis lipopolysaccharide stimulated proinflammatory cytokine expressions and nuclear factor-kappa $\mathrm{B}$ activation in human gingival fibroblasts. J Periodontal Res 50: 380-388, 2015.

16. Bachrach G, Jamil A, Noar R, Tal G, Ludmer Z and Steinberg D: Garlic allicin as a potential agent for controlling oral pathogens. J Med Food 14: 1338-1343, 2011.

17. Bakri IM and Douglas CW: Inhibitory effect of garlic extract on oral bacteria. Arch Oral Biol 50: 645-651, 2005.

18. Velliyagounder K, Ganeshnarayan K, Velusamy SK and Fine DH: In vitro efficacy of diallyl sulfides against the periodontopathogen Aggregatibacter actinomycetemcomitans. Antimicrob Agents Chemother 56: 2397-2407, 2012

19. Kodera Y, Ushijima M, Amano H, Suzuki JI and Matsutomo T: Chemical and biological properties of $S$-1-propenyl-L-cysteine in aged garlic extract. Molecules 22: 570, 2017.

20. Livak KJ and Schmittgen TD: Analysis of relative gene expression data using real-time quantitative PCR and the 2(-Delta Delta C(T)) method. Methods 25: 402-408, 2002

21. Hosokawa Y, Hosokawa I, Ozaki K, Nakae H and Matsuo T: Cytokines differentially regulate ICAM-1 and VCAM-1 expression on human gingival fibroblasts. Clin Exp immunol 144 494-502, 2006.

22. Kato Y, Hagiwara M, Ishihara Y, Isoda R, Sugiura S, Komatsu T, Ishida N, Noguchi $\mathrm{T}$ and Matsushita K: TNF- $\alpha$ augmented Porphyromonas gingivalis invasion in human gingival epithelia cells through Rab5 and ICAM-1. BMC Microbiol 14: 229, 2014.
23. Liu J, Duan J, Wang Y and Ouyang X: Intracellular adhesion molecule-1 is regulated by Porphyromonas gingivalis through nucleotide binding oligomerization domain-containing proteins 1 and 2 molecules in periodontal fibroblasts. J Periodontol 85: 358-368, 2014.

24. Song H, Zhao H, Qu Y, Sun Q, Zhang F, Du Z, Liang W, Qi Y and Yang P: Carbon monoxide releasing molecule-3 inhibits concurrent tumor necrosis factor- $\alpha$ - and interleukin- $1 \beta$-induced expression of adhesion molecules on human gingival fibroblasts. J Periodontal Res 46: 48-57, 2011.

25. Tancharoen S, Matsuyama T, Abeyama K, Matsushita K, Kawahara K, Sanqalungkam V, Tokuda M, Hashiguchi T, Maruyama I and Izumi Y: The role of water channel aquaporin 3 in the mechanism of TNF-alpha-mediated proinflammatory events: Implication in periodontal inflammation. J Cell Physiol 217: 338-349, 2008.

26. Bian T, Li H, Zhou Q, Ni C, Zhang Y and Yan F: Human $\beta$-defensin 3 reduces TNF- $\alpha$-induced inflammation and monocyte adhesion in human umbilical vein endothelial cells. Mediators Inflamm 2017: 8529542, 2017.

27. Nennig SE and Schank JR: The role of NFkB in drug addiction: Beyond inflammation. Alcohol Alcohol 52: 172-179, 2017.

28. Yamaguchi H, Ishida Y, Hosomichi J, Suzuki JI, Usumi-Fujita R, Shimizu Y, Kaneko S and Ono T: A new approach to transfect $\mathrm{NF}-\kappa \mathrm{B}$ decoy oligodeoxynucleotides into the periodontal tissue using the ultrasound-microbubble method. Int J Oral Sci 9: 80-86, 2017.

29. Cui D, Lyu J, Li H, Lei L, Bian T, Li L and Yan F: Human $\beta$-defensin 3 inhibits periodontitis development by suppressing inflammatory responses in macrophages. Mol Immunol 91: 65-74, 2017

30. Li S, Song Z, Dong J and Shu R: MicroRNA-142 is upregulated by tumor necrosis factor-alpha and triggers apoptosis in human gingival epithelial cells by repressing $\mathrm{BACH} 2$ expression. Am J Transl Res 9: 175-183, 2017

31. Lawson C and Wolf S: ICAM-1 signaling in endothelial cells. Pharmacol Rep 61: 22-32, 2009.

32. Lyck R and Enzmann G: The physiological roles of ICAM-1 and ICAM-2 in neutrophil migration into tissues. Curr Opin Hepatol 22: 53-59, 2015.

33. Liu CW, Sung HC, Lin SR, Wu CW, Lee CW, Lee IT, Yang YF, Yu IS, Lin SW, Chiang MH, et al: Resveratrol attenuates ICAM-1 expression and monocyte adhesiveness to TNF- $\alpha$-treated endothelial cells: Evidence for an anti-inflammatory cascade mediated by the miR-221/222/AMPK/p38/NF- $\kappa$ B pathway. Sci Rep 7: 44689, 2017.

34. Yan W, Zhao K, Jiang Y, Huang Q, Wang J, Kan W and Wang S: Role of p38 MAPK in ICAM-1 expression of vascular endothelial cells induced by lipopolysaccharide. Shock 17: 433-438, 2002.

35. Zhao W, Feng H, Guo S, Han Y and Chen X: Danshenol A inhibits TNF- $\alpha$-induced expression of intercellular adhesion molecule-1 (ICAM-1) mediated by NOX4 in endothelial cells. Sci Rep 7: 12953, 2017.

36. Imai H, Fujita T, Kajiya M, Ouhara K, Yoshimoto T, Matsuda S, Takeda K and Kurihara H: Mobilization of TLR4 into lipid rafts by Aggregatibacter actinomycetemcomitans in gingival epithelial cells. Cell Physiol Biochem 39: 1777-1786, 2016.

37. Hosokawa Y, Hosokawa I, Ozaki K and Matsuo T: IL-27 modulates chemokine production in TNF- $\alpha$-stimulated human oral epithelial cells. Cell Physiol Biochem 43: 1198-1206, 2017.

38. Güncü GN, Yilmaz D, Könönen E and Gürsoy U: Salivary antimicrobial peptides in early detection of periodontitis. Front Cell Infect Microbiol 5: 99, 2015.

39. Tanaka T, Narazaki M and Kishimoto T: IL-6 in inflammation, immunity, and disease. Cold Spring Harb Perspect Biol 6 : a016295, 2014.

40. Ahn SH, Lee JK, Kim ND, Kim SH, Lee S, Jung S, Chay KO and Lee TH: [2-(1,2-diphenyl-1H-indol-3-yl)ethanamine] augments pro-inflammatory cytokine production in IL-1b-stimulated primary human oral cells. Int J Mol Sci 19: 1835, 2018. 